NASA Technical Memorandum 87197

\title{
Mass Balancing of Hollow Fan Blades
}

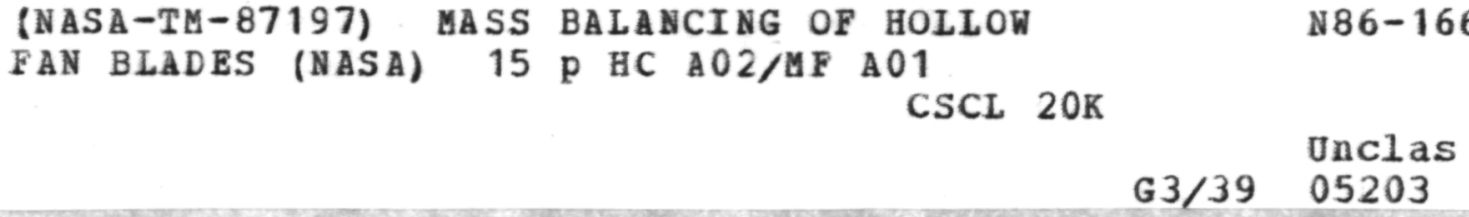

Robert E. Kielb

Lewis Research Center

Cleveland, Ohio

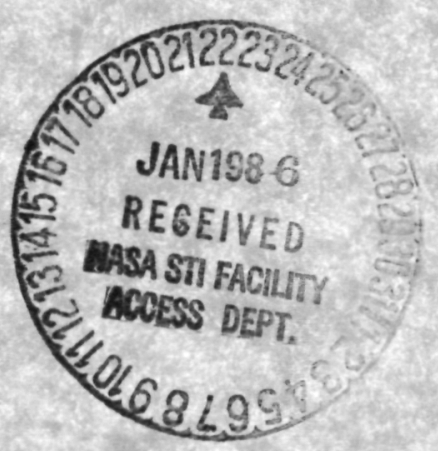

Prepared for the

31st International Gas Turbine Conference

sponsored by the American Society of Mechanical Engineers

Dusseldorf, West Germany, June 8-12, 1986

\section{NRSA}


MASS BALANCING OF HOLLOW FAN BLADES

Robert E. Kield

National Aeronautics and Space Administration

Lewis Research Center

Cleveland, Onio 44135

ABSTRACT

This paper uses a typical section model to analytically investigate the effect of mass balancing as applied to hollow, supersonic fan blades. A procedure to determine the best configuration of an internal balancing mass to provide flutter alleviation is developed. This procedure is applied to a typical supersonic snroudless fan blade which is unstable in both the solid configuration and when it is hollow with no balancing mass. The addition of an optimized balancing mass is snown to stabilize the blade at the design condition.

\section{NOMENCLATURE}

a

$a_{e}$

b

C

$c_{m}$

$c_{m r}$

g

$g_{r}$

[I]

I

$I_{X X}$

J

K

$K_{n}$ sonic velocity

elastic axis position

semichord

chord

chordwise dimension of balancing mass

$c_{m} / b$

thickness of gap region

$g / t$

identity matrix

polar mass moment of inertia about elastic axis

area moment of inertia about $x$ axis

torsion stiffness coefficient

torsion stiffness

Dending stiffness k

$k_{f}$

L

$T_{\mathrm{hh}}, \mathrm{T}_{\mathrm{h} \alpha}$

$l_{\alpha h}, l_{\alpha \alpha}$

M

$M_{e}$

m

$m_{r}$

$r_{\alpha}$

$S_{\alpha}$

$\mathrm{S}$

t

$t_{r}$

V

W

$w_{r}$

$x_{\alpha}$

$x_{m}$

$x_{p}$

$x_{p d}$

$x_{m r}$ reduced frequency, $\omega b / V$

flutter reduced frequency

aerodynamic lift

nondimensional lift due to plunging and pitching motions, respectively

nondimensional moment due to plunging and pitching motions, respectively

Mach number of freestream relative to blade aerodynamic moment

mass per unit span of blade

$\mathrm{m} /$ ( $\mathrm{m}$ of solid blade)

nondimensional radius of gyration

mass moment about elastic axis

circumferential gap between adjacent blades

blade thickness

thickness ratio, t/c

freestream air velocity relative to blade

thickness of blade wall

$w / t$

dimensionless static unbalance

chordwise location of balancing mass

nondimensional pitcning axis location

pitching axis location selected for design

$x_{m} / b$ 


$\begin{array}{ll}\gamma_{\alpha} & \text { nondimensional uncoupled torsion fr } \\ \gamma_{h} & \text { nondimensional uncoupled bending fr } \\ \xi & \text { stagger angle } \\ \zeta & \text { critical damping ratio } \\ \lambda & \text { nondimensional eigenvalue } \\ \mu & \text { mass ratio, } \mathrm{m} / \pi \mathrm{b}^{2} \\ \rho & \text { density of } \mathrm{Dlade} \text { material } \\ \rho_{\mathrm{a}} & \text { air density } \\ \rho_{\mathrm{m}} & \text { density of balancing mass material } \\ \rho_{\mathrm{mr}} & \rho_{\mathrm{m}} / \rho \\ \tau & \text { time } \\ \omega & \text { frequency } \\ \omega^{\star} & \text { nondimensional frequency, wb/a } \\ \omega_{d}^{\star} & \text { nondimensional design frequency } \\ \omega_{\mathrm{f}}^{\star} & \text { nondimensional flutter frequency } \\ \omega_{\mathrm{n}} & \text { bending frequency } \\ \omega_{\alpha} & \text { torsion frequency }\end{array}$

INTRODUCTION

One objective of the research at NASA Lewis is to develop the technology to allow improved fan blade designs. Aeroelastic considerations currently prevent the operation of efficient, lightweight, unshrouded fan blades. To alleviate flutter prodlems of such blades, recent research has investigated concepts such as mistuning and passive damping. However, relatively little attention has been given to the classical aeroelastic concept of mass balancing.

Mass balancing refers to the systematic distribution of mass for the purpose of alleviating aeroelastic instabilities. Tris concept has been recognized and utilized since the earliest days of aeroelastic researcn. Perhaps the first treatment of this subject was by von Baumhauer and Konig (1). In this work the effect of adding appropriately positioned weights to a wing was shown to alleviate a flutter problem. A comprehensive study of the effect of center of mass location is given in a classical paper by Theodorsen and Garrick (2). For incompressiole flow they show that the parameter controlling the instability is dependent on the value of the bending-to-torsion frequency ratio $\left(\omega_{n} / \omega_{\alpha}\right)$. For low values of $\omega_{h} / \omega_{a}(\approx 0)$ the instability is controlled by the center of mass offset from the aerodynamic center. For higher values of $\omega_{h} / \omega_{\alpha}$ the instability is controlled by the center of mass offset from the elastic axis. These trends are also shown to hold for supersonic flow in the work of Ashley and Zartarian (3). Approximate rules for frequency coalescence flutter are given by Pines (4). These rules state that flutter is not possible for the case where tne center of mass is forward of the elastic axis. When the center of mass is behind the elastic axis the possibility of flutter is dependent on the system parameters.

The concepts described above have been extensively used in the designs of fixed wings (e.g., the placement of wing mounted engines), helicopter blades, rockets, and satellites. In the past fan blades have been of solid construction due to the inability to manufacture practical hollow blades. Thus, little design freedom has been available in distributing the blade mass and is one explanation for the lack of research in mass balancing as applied to fan blades. However, recent manufacturing technology breaktnroughs have led to the development of hollow fan blades such as tne configuration shown in Fig. 1. With the introduction of the internal voids in the airfoil, the designer has mucn greater latitude in distriduting mass.

Although the author knows of no publications that explicitly treat the effect of mass balancing on a cascade of Dlades, at least two recent papers give results which implicitly address the subject. Reference 5 shows the stability characteristics of a cascade in incompressible flow with the center of gravity at mid-chord and the elastic axis at 25, 50, and 75 percent chord for a variety of bending to torsion frequency ratios. For bending-to-torsion frequency ratios less than one the 75 percent chord location is shown to have the highest flutter speed. For ratios greater than one the 25 percent chord location is the best. A comprehensive study of the effect of elastic axis and center of mass location on supersonic fan blade stability is given in Ref. 6. The elastic axis was fixed at mid-chord and the center of gravity was located at a variety of positions aft of mid-chord. In general, it was found that positions ahead of the center of gravity were beneficial for bending-to-torsion frequency ratios less than one (which is normally the case when considering the first bending and torsion modes) and detrimental for ratios greater than one. In simulating a typical supersonic fan blade with the center of mass at mid-chord, the best elastic axis position was found to be near 75 percent chord, which is in agreement with Ref. 5 . Neither of the Ref. 5 or 6 studies determined the optimum mass balanced configuration. Some additional experimental and analytical studies which consider the effect of elastic axis and center of mass location on flutter are given in Refs. 7 and 8.

The objective of tnis paper is to investigate the effect of mass balancing on hollow, supersonic fan blades and to provide the designer with a method to optimally distribute the blade mass for maximum flutter alleviation. A supersonic hollow fan blade with an internal balancing mass is studied by using a typical section model. Procedures to determine the best balancing mass configuration are given. Only high speed, supersonic, unstalled flutter is considered.

\section{THEORY}

The actual cross section of a hollow blade may appear as shown Fig. 1. For the purposes of this study the cross section is idealized as snown in Fig. 2 , in which the blade is assumed to consist of two thin walls separated by "massless stiffeners" which form a hollow region. In this gap region is a balancing mass which has the same thickness as the gap and has a variable chordwise dimension and location. The variables are limited to cases where the balancing mass does not protrude from the thin walls. The balancing mass is assumed to be nonstructural and can have a different density from the blade wall material. This idealization simplifies the model yet maintains the basic physics of the mass balancing phenomenon. The following nondimensional ratios are used to define a mass balancing configuration. 


$$
\begin{aligned}
\mathrm{t}_{r} & =\mathrm{t} / \mathrm{c} \\
\mathrm{w}_{r} & =\mathrm{w} / \mathrm{t} \\
\mathrm{g}_{r} & =\mathrm{g} / \mathrm{t} \\
\mathrm{c}_{\mathrm{mr}} & =\mathrm{c}_{\mathrm{m}} / \mathrm{b} \\
\mathrm{x}_{\mathrm{mr}} & =\mathrm{x}_{\mathrm{m}} / \mathrm{b} \\
\rho_{m r} & =\rho_{m} / \rho
\end{aligned}
$$

As in Refs. 5, 6, and 9 the blade is modeled as a two degree of freedom oscillator in which the plunging and pitching motions are inertially coupled (see Fig. 3). In the following only a brief summary of the governing equations is given. For a more detailed description see one or more of the above references. The blades' motion is assumed to be simple harmonic with a constant phase angle between adjacent blades. With this assumption the equation of motion for a single blade (neglecting structural damping) is

$$
\left[\begin{array}{cc}
m & S \alpha \\
S \alpha & I \alpha
\end{array}\right]\left\{\begin{array}{ll}
\frac{d^{2}}{d t^{2}}\left(n e^{i \omega \tau}\right) \\
\frac{d^{2}}{d t^{2}}\left(\alpha e^{i \omega \tau}\right)
\end{array}\right\}+\left[\begin{array}{ll}
K_{h} & 0 \\
0 & K_{\alpha}
\end{array}\right]\left\{\begin{array}{l}
n e^{i \omega \tau} \\
\alpha e^{i \omega \tau}
\end{array}\right\}=\left\{\begin{array}{l}
-L \\
M_{e}
\end{array}\right\}
$$

The unsteady aerodynamic loads are defined in terms of the linear lift and moment coefficients as

$$
\begin{aligned}
& L=-\pi \rho_{a} b^{3} \omega^{2}\left(1_{h n} \frac{h}{b}+1_{h \alpha} \alpha\right) e^{i \omega \tau} \\
& M=\pi \rho b^{4} \omega^{2}\left(1_{\alpha n} \frac{h}{b}+1_{\alpha \alpha} \alpha\right) e^{i \omega \tau}
\end{aligned}
$$

After nondimensionalizing and putting in standard eigenvalue form the equation becomes

$$
\left[\begin{array}{ll}
\frac{1}{\gamma_{h}^{2}}\left(1+\frac{1_{h h}}{\mu}\right) & \frac{1}{\gamma_{h}}\left(x_{\alpha}+\frac{I_{h \alpha}}{\mu}\right) \\
\frac{1}{r^{2} \gamma^{2}}\left(x_{\alpha}+\frac{I_{\alpha h}}{\mu}\right) & \frac{1}{\gamma_{\alpha}^{2}}\left(1+\frac{I_{\alpha \alpha}}{\mu r^{2}}\right)
\end{array}\right]-\lambda[I]=0
$$

The variables $r h$ and $\gamma_{\alpha}$ are nondimensionalized with respect to the natural frequencies of the solid blade.

$$
\gamma_{h}^{2}=\frac{\left(\frac{K_{h}}{m}\right)_{\text {hollow }}}{\left(\frac{K_{h}}{m}\right)_{\text {solid }}} \text { and } \gamma_{\alpha}^{2}=\frac{\left(\begin{array}{l}
K_{\alpha} \\
I_{\alpha}
\end{array}\right)_{\text {hollow }}}{\left(\frac{K_{\alpha}}{I_{\alpha}}\right)_{\text {solid }}}
$$

Aaditional variables are defined in the nomenclature.

The stability characteristics of the system can be determined by iteratively solving the complex eigenvalue problem of Eq. (4). For a given system the stability characteristics can be found by choosing a Mach number and interblade phase angle and iterating on reduced frequency until the calculated frequencies are consistent with the assumed reduced frequency and Mach number. The aerodynamic damping for that Mach number and interblade phase angle can then be calculated. Tnis procedure should de repeated for various Mach numbers and interblade phase angles until tne neutral stability point is determined.

To determine the effects of the balancing mass this procedure could be followed for various balancing mass configurations. The predicted flutter Mach numbers for each configuration could then be compared to determine the best. However, to find the best configuration using this procedure would require an unnecessarily large number of configurations to be analyzed. Following is a description of a more efficient method. It is helpful to pay attention to the pitching axis location associated with any mode of interest. The location of the pitching axis for a typical section is the point along the chordline which experiences no plunging motion when the blade oscillates in some mode, and is not the same as the elastic axis (locus of shear centers) used in the two degree of freedom analysis. As shown is Ref. 6 , the predicted stability characteristics can be drastically different from one and two degree of freedom flutter analyses if the pitching axis for tne one degree of freedom analysis is assumed to be the blade elastic axis. However, for a given elastic axis (and other defined blade properties), a pitching axis can be found for every mode shape, and the one degree of freedom analysis can be used to estimate the stability of the mode based on that pitching axis. This estimate will be very accurate as long as the frequency of the modes are separated by at least 10 percent (see $(5)$ and (6)). In the following it is assumed that the single degree of freedom flutter analysis can be used to find the best pitching axis location. Note that in the present work the balancing mass is assumed to add no stiffness, therefore, the position of the elastic axis is the same for all mass balancing configurations.

For a single degree of freedom flutter analysis the neutral stability condition, with respect to the system variables, can be simply determined by finding the point where the imaginary part of the moment coefficient vanisnes (or the lift coefficient for pure plunging motion). For a fixed stagger angle and gap-to-chord ratio, the reduced frequency $\left(k_{f}\right)$ at which the imaginary part vanishes should be calculated for the Mach number range of interest for various pitching axis locations (normally a range from the leading edge to four semi-chords downstream is sufficient). These calculations will show the pitcning axis location, $x_{p d}$, which results in the dest stability characteristics over the chosen range of Mach numbers. They will also yield the derodynamically required minimum value of the modal frequency for the mass balanced blade. (Note the best overall pitching axis location may not be the best at any single Macn number, such as that of the design point.) It is useful to define the following nondimensional frequencies $(\underline{10})$.

$$
\omega^{*}=k M \text { and } \quad \omega_{f}^{*}=k_{f} M
$$

Denote the nondimensional frequency, required by aerodynamics, for the mass balanced blade as wd. This is the minimum frequency which results in a stable blade for the chosen pitching axis location over the entire Mach number range of interest.

The next step is to find the best mass balancing configuration which results in a pitching axis at $x_{p d}$ and a frequency of wd or greater. Because the aerodynamic forces normally cause very little change in blade frequencies (for supersonic fans), we can neglect them. In the absence of these forces Eq. (2) simplifies to a real eigenvalue analysis from which the uncoupled 
modal frequencies and mode shapes of the inertially coupled system can be determined.

$$
\left[\begin{array}{ll}
\frac{1}{2} & \frac{x_{\alpha}}{\gamma_{h}} \\
\frac{\gamma_{h}}{x_{\alpha}} & \frac{1}{r^{2} \gamma_{\alpha}^{2}} \\
r_{\alpha}^{2}
\end{array}\right]-\lambda[I]=0
$$

Using simple cantilever beam expressions these variables can be defined in terms of the geometric and material properties.

$$
\gamma_{h}^{2}=\frac{\left(\frac{I_{x x}}{m}\right)_{\text {holiow }}}{\left(\frac{I_{x x}}{m}\right)_{\text {solio }}} \text { and } \gamma_{\alpha}^{2}=\frac{\left(\frac{J}{I_{\alpha}}\right)_{\text {hollow }}}{\left(\frac{J}{I_{\alpha}}\right)_{\text {solid }}}
$$

Next these quantities can be expressed in terms of the nondimensional parameters defining the mass balancing configuration.

$$
\begin{aligned}
r_{h}^{2} & =\left(1-g_{r}^{3}\right) /\left(2 \omega_{r}+\frac{\rho_{m r} c_{m r} g_{r}}{2}\right) \\
r_{\alpha}^{2}=3\left(\frac{\omega_{\alpha}}{\omega_{h}}\right)_{\text {solid }}{ }^{w_{r}}\left(1-w_{r}\right)^{2}\left(1+t_{r}^{2}\right) & {\left[w_{r}\left(1+w_{r}^{2} t_{r}^{2}+3 t_{r}^{2}\left(1-w_{r}\right)^{2}\right)\right.} \\
+ & \left.\frac{\rho_{m r} c_{m r} g_{r}}{4}\left(\frac{c_{m r}^{2}}{4}+t_{r}^{2} g_{r}^{2}+3 x_{m r}^{2}\right)\right]
\end{aligned}
$$

The radius of gyration, static unbalance, and mass ratio can also be expressed in terms of these nondimensional parameters

$$
\begin{gathered}
r_{\alpha}^{2}=2\left\{w_{r}\left[1+w_{r}^{2} t_{r}^{2}+3 t_{r}^{2}\left(1-w_{r}\right)^{2}\right]\right. \\
\left.+\frac{\rho_{m r} c_{m r} g_{r}}{4}\left(\frac{c_{m r}^{2}}{4}+t_{r}^{2} g_{r}^{2}+3 x_{m r}^{2}\right)\right\} / 3\left(2 w_{r}+\frac{\rho_{m r} c_{m r} g_{r}}{2}\right) \\
x_{\alpha}=\left(x_{m r} \rho_{m r} c_{m r} g_{r}\right) /\left(4 w_{r}+\rho_{m r} g_{r} c_{m r}\right) \\
\mu=\mu_{\text {solid }}\left(2 w_{r}+\frac{\rho_{m r} c_{m r} g_{r}}{2}\right)
\end{gathered}
$$

When solving Eq. (7) the following trends are found. As the centroid of the balancing mass moves away from the elastic axis position, the frequencies of both normal modes decrease. By itself this decrease would tend to reduce the stability of the system because it lowers the reduced frequency. However, the coupling between the plunging and pitching motions increases. If this coupling moves the picching axis for one of the modes near to the "best" location (determined from the single degree of freedom flutter analysis described above), an overall beneficial effect on the stability may be found. Therefore, the balancing mass has competing detrimental and beneficial effects. Which of these effects dominates depends on the parameters of the blade Deing studied. For some blades the effect of the reduction of frequency is so strong that the blade cannot be practically stabilized with mass balancing. Tnese competing effects will be shown graphically in the example of the following section.

There can be many mass balancing configurations which result in the same required pitching axis location and frequency as determined from the single degree of freedom flutter analysis. To efficiently find the best mass balancing configuration, the following sequence of solutions of Eq. (7) should be followed.

To result in a mass balanced blade with modal frequencies as high as possible, the density ratio should De chosen as large as possible. The reason is that, for a fixed balancing mass (the quantity and location), the area and polar mass moment of inertia decrease as the density of the balancing mass increases, and the frequency increases as the polar mass moment of inertia decreases. A common material having a high density is tungsten. The density ratio, $\rho_{\mathrm{mr}}$, for a tungsten balancing weignt is approximately 4 for a titanium blade and 7 for an aluminum blade.

Next select a chordwise dimension for the balancing mass, $\mathrm{c}_{\mathrm{mr}}$, (usually less than 0.5) and determine the location of the balancing mass, $x_{m r}$, which results in a pitching axis at $x_{p d}$. This can be done by iteratively solving Eq. (7). Repeat this process for other values of $c_{m r}$ until the value is found which results in an acceptable frequency $\left(\omega^{*}>\omega_{d}^{*}\right)$ and the lowest mass per unit span, $m_{r}$.

In the above discussion emphasis has been placed on only one mode of the system. For high speed fan flutter this is normally the torsional mode, which is represented in this model as pitching about some point near mid-chord. However, it may be found that as tnis predominantly torsion mode is stabilized the predominantly bending mode is destabilized. Therefore, when a stable configuration for the one mode is found, the otner mode must be checked for stability.

Once the above procedure is followed to find the best mass balancing configuration, a two (or multi) degree of freedom flutter analysis should be used to accurately define the stability characteristics of the mass balanced design.

In summary, the steps to define the best mass balancing configuration for fixed values of $t_{r}$ and $\mathrm{w}_{\mathrm{r}}$ are:

(1) For the fixed values of the stagger angle and gap-to-chora ratio (usually taken near 75 percent span) construct a plot of aerodynamically required frequency, $\omega$ f , versus pitching axis location by finding where the imaginary part of the moment coefficient vanishes. Determine the "best" location, $x_{\text {pd }}$, and the frequency, $\omega \hat{d}$ that exceeds $\omega_{f}^{\star}$ over the Mach number $r$ ange of interest.

(2) Select a balancing mass material with as high a density as possible and determine the density ratio, $\rho_{\mathrm{mr}}$.

(3) Iteratively solve Eq. (7) for selected values of $c_{m r}$ to determine the balancing mass location, $x_{m r}$, which results in a pitching axis at $x_{\text {pd }}$. For this configuration determine the blade modal frequency, $\omega^{\star}$, and mass per unit span, $m_{r}$.

(4) From the resuits of step 3 determine the value of $\mathrm{C}_{\mathrm{mr}}$ which results in a modal frequency, $\omega^{\star}$, greater than or equal to $\omega_{d}$ and has the lowest total blade mass. If the frequencies are all less than $\omega_{d}^{\star}$, this olade is not good candidate for mass balancing using the selected density ratio. 
(5) Using the configuration from step 4 perform a complete multi degree of freedom flutter analysis for all modes to cneck that you have a stable design.

In the above steps it is important to consider all possible interblade phase angles when calculating $\mathrm{k}_{\mathrm{f}}$ and system stability. The example in the following section further clarifies the above discussion.

\section{RESULTS ANO DISCUSSION}

An advanced unshrouded fan stage representative of a next-generation fan was chosen for analysis. A similar blade was analyzed in Ref. 12 to investigate mistuning effects. The properties of this blade (in the solid configuration) at the design condition are given in Table 1. The aspect ratio of the blade is 3.1 and the stage contains 28 blades. At the design point (tip relative Mach number is 1.45) the blade encounters high speed unstalled torsional flutter in both the solid and nollow (with no balancing mass) configuration. This section give an example of an efficient method to find the oest mass balancing configuration to stabilize the blade.

For tnis example the unsteady aerodynamic coefficients in Eq. (3) are calculated by using Adamczyk and Goldstein's tneory (11) for a cascade in supersonic flow with a subsonic Teading edge. In this theory the effect of airfoil thickness, camber, and steady state angle of attack are neglected, and the flow is assumed to be isentropic and irrotational. For more information see (11).

The dependence of aerodynamically required frequency, $\omega_{f}^{\star}$, on Mach number for selected pitching axis locations is snown in Fig. 4. As can be seen, the nollow blade with no balancing mass $\left(\omega^{*}=0.725\right.$ and $x_{p}=0.0$ ) would encounter a strong instability just below the design point. As the pitching axis moves toward the leading edge, the required frequency is significantly reduced for the design Mach number. Although not snown, the minimum required frequency (for $M=1.27$ ) is acnieved with the pitching axis at $x_{p}=-0.37$. However, for pitching axis locations forward of midchord, the required frequency is significantly increased at lower Mach numbers. Note that unsteady aerodynamics theory used nerein gives unreliable results as the Mach number approaches one. For pitching axis locations aft of mid-chord the effect is reversed, i.e., the required frequency is increased for the higher Mach numbers and decreased for the lower. The best pitching axis location is one which reduces the required frequency for the design condition, but does not affect the lower Macn number conditions to a serious extent. As seen in Fig. 4, the pitcning location of -0.24 (38 percent chord) results in a relatively constant required frequency over the Mach number range of interest. As a result, this value was chosen as the best.

It may appear from Fig. 4 that a pitching axis location near the trailing edge $\left(x_{p}>0.5\right)$ would be desirable, however the frequency of the modes with these pitcning axis locations drops to such an extent that it is substantially less than the frequency required at the design point.

The aerodynamic theory used herein predicts that there can be no pure bending flutter (pitcning axis at infinity). Therefore the curves in Fig. 4 approach zero for all Mach numbers as $x_{p}$ approaches positive and negative infinity. For values of $x_{p}$ greater than 4 the value of $\omega_{f}^{\star}$ at the design Mach number is less than 0.18 . The predominantly bending mode ( $\omega *$ approximately 0.25 ) for this blade was found to be stable when $x_{p}$ is greater than 3.5, however, this mode could be easily destabilized by positioning a large balancing mass near the leading edge.
As mentioned previously all possible interblade phase angles must be considered when constructing Fig. 4. Althougn the critical interblade phase angle varies with pitching axis location, it was found that the interblade phase angles in the range of $38.6^{\circ}$ to $64.3^{\circ}$ ( 3 to 5 nodal diameter forward traveling waves) were critical for most of the cases.

A tungsten balancing mass was selected. Since the blade being considered is titanium, a density ratio of 4 was used. The real eigenvalue problem of Eq. (7) was solved for various values of $c_{m r}$ and $x_{m r}$. An example of the effect of balancing mass position on both frequency and mode shape is shown in $\mathrm{Fig}$. 5 for $\mathrm{c}_{\mathrm{mr}}=0.22$ (as will be shown below this is the best value). The location of the mass has a much stronger effect on the torsion mode than on bending mode. To obtain the required pitching axis location, -0.24 , the balancing mass must be located at -0.5 ( 25 percent chord). Although the frequency, $\omega^{*}$, of the mode has decreased significantly it is still above the aerodynamically required value, $\omega_{d}^{\star}$. Note that the frequency curves of Fig. 5 are symmetric about $x_{m r}=0.0$ (the pitching axis curve is anti-symmetric).

The curves shown in Fig. 5 were generated for other values of $c_{m r}$ and the values of $\omega^{*}$ and $m_{r}$ for which $x_{p}=-0.24$ were determined. The resulting blade frequencies are shown in Fig. 6 as a function of the blade mass. In addition to a curve for the selected frequency ratio of 4 , Fig. 6 includes curves for ratios of one and infinity (a point mass). As can be seen a nigher density ratio will result in a lower blade mass to achieve a given frequency. For the chosen density ratio $\left(\rho_{m r}=4\right)$ the curve peaks at a maximum obtainable frequency of slightly over 0.65 . Fortunately, this is slightly above the aerodynamically required value of 0.646 . If the required value is greater than 0.651 , this blade could not be stabilized with this density ratio. The value of $m_{r}$ corresponding to the desired frequency is 0.664 . This represents the fraction of blade mass as compared to the solid blade and is 1.66 times the mass of the hollow Dlade without a balancing mass $\left(m_{r}=0.4\right)$. Thus, a significant weight penalty has been paid in stabilizing the hollow blade. As a result, the best mass balancing configuration for flutter suppression may not be the best when considering the whole engine and all design requirements. If the increase in engine weight is not tolerable, other passive flutter suppression schemes such as damping and/or mistuning may be more desirable.

A summary of the aerodynamic damping for the solid, hollow (with no balancing mass) and best mass balanced configurations is shown in Fig. 7. The solid blade is seen to be unstable for all Mach numbers shown. A significant improvement in blade stability can be achieved by making the blade hollow. This is simply due to the increase in frequency of the torsional mode. However, the blade still encounters a strong instability below the design point. The best mass balancing configuration is shown to eliminate the instability completely. As was seen in Fig. 4, the aerodynamically required blade frequencies are very sensitive to the pitching axis location. For example, the best mass balanced configuration has $x_{p}=-0.24$, yet if the pitching axis is moved slightly to -0.30 , the olade ( which has $\omega^{*}=0.65$ ) would experience an instability at lower Mach numbers. The range of $x_{p}$ over which the blade is stable for $1.1<M<1.3$ is relatively narrow. Furthermore as previously noted, the bending mode can be destabilized when adding a balancing mass. These sensitivities imply that the designer must be extremely careful in choosing the configuration of the balancing mass. 


\section{SUMMARY AND CONCLUSIONS}

An efficient procedure for assessing mass balancing as a passive means to alleviate flutter for fan blades is presented. The procedure is applied to an unstalled, supersonic fan blade which encounters high speed, unstalled supersonic flutter. A mass balancing configuration is defined which stabilizes the blade over the desired operating range. The major conclusions from this investigation are the following:

1. For the particular blade studied the best location for the pitching axis of the predominantly torsional mode is at 38 percent chord.

2 . The best mass balanced configuration was one with a mass centered at 25 percent chord, a chordwise length of 11 percent of the blade chord, and a density four times that of the blade wall.

3. Because of the sensitivity of blade stability to pitching axis location and the possibility that the predominantly bending mode may be destabilized, a careful procedure to define the balancing mass configuration, sucn as that given herein, is required. 4. A major improvement in blade stability can be realized by using a hollow blade with no balancing mass. 5. The mass penalty which must be paid to stabilize the blade may be so large tnat other blade and engine design requirements may be affected.

\section{REFERENCES}

1. Baumhauer, A.G. von and Koning, C., "On the Stability of Oscillations of an Airplane Wing," NACA TM-223, 1923.

2. Theodorsen, T. and Garrick, I.E., "Mechanism of Flutter-A Theoretical and Experimental Investigation of the Flutter Problem, " NACA Report $685,1940$.
3. Ashley, H. and Zartarian, G., "Supersonic Flutter Trends as Revealed by Piston Theory Calculations," USAF Wright Air Development Center Technical Report 58-74, May 1958.

4. Pines, S., "An Elementary Explanation of the Flutter Mechanism," Dynamics and Aeroelasticity, Proc. Natl. Specialists Meeting on Dynamics and Aeroelasticity, Ft. Worth, Texas, Nov. 1958, pp. 52-58.

5. Kaza, K.R.V. and Kielb, R.E., "Flutter and Response of a Cascade Mistuned in Incompressible Flow", AIAA Journal, Vol. 20, No. 8, Aug. 1982, pp. 1120-1127.

6. Bendiksen, 0. and Friedmann, P., "Coupled Bending-Torsion Flutter in Cascades, " AIAA Journal, Vol. 18, No. 2, Feb. 1980, pp. 194-201.

7. Troha, W. and Swain, K., "Composite Inlays Increase Flutter Resistance of Turbine Engine Fan Blades," ASME Paper 76-GT-29, Mar. 1976.

8. Carta, F.0., "Coupled Blade-Disk-Shroud Flutter Instabilities in Turbojet Engine Rotors," Journal of Engineering for Power, Vol. 89, No. 3, July 1967, pp. 419-426.

9. Kielb, R.E. and Kaza, K.R.V., "Aeroelastic Characteristics of a Cascade of Mistuned Blades in Subsonic and Supersonic Flows," Journal of Vibration, Acoustics, Stress, and Reliability in Design, Vol. 105, No. 2, Apr. 1983, pp. 425-433.

10. Brown, G.V., NASA Lewis Research Center, Private Communication on Nondimensional Frequency.

11. Adamczyk, J.J. and Goldstein, M.E., "Unsteady Flow in a Supersonic Cascade with Subsonic Leading-Edge Locus, " AIAA Journal, Vol. 16, No. 12, Dec. 1978, pp. $1248-1254$.

12. Kaza, K.R.V. and Kielb, R.E., "Flutter of Turbofan Rotors with Mistuned Blades," AIAA Journal, Vol. 22, No. 11, Nov. 1984, pp., 1618-1625. 
TABLE I. - SOLID BLADE PROPERTIES - 75 PERCENT SPAN, DESIGN POINT

Thickness ratio, $R_{t}$........... 0.037

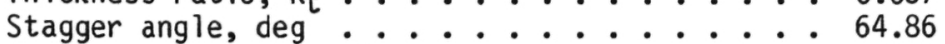

Gap-to-chord ratio, s/c . . . . . . . 0.8

Mass ratio ....................... 206

Radius of gyration, $r_{\alpha}$........... 0.5774

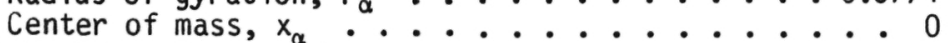

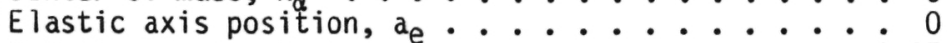

Relative design Mach number ......... 1.27

Reduced frequency for bending mode . . . . 0.194

Reduced frequency for torsion mode . . . . . 0.412

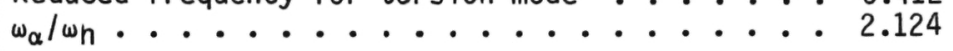




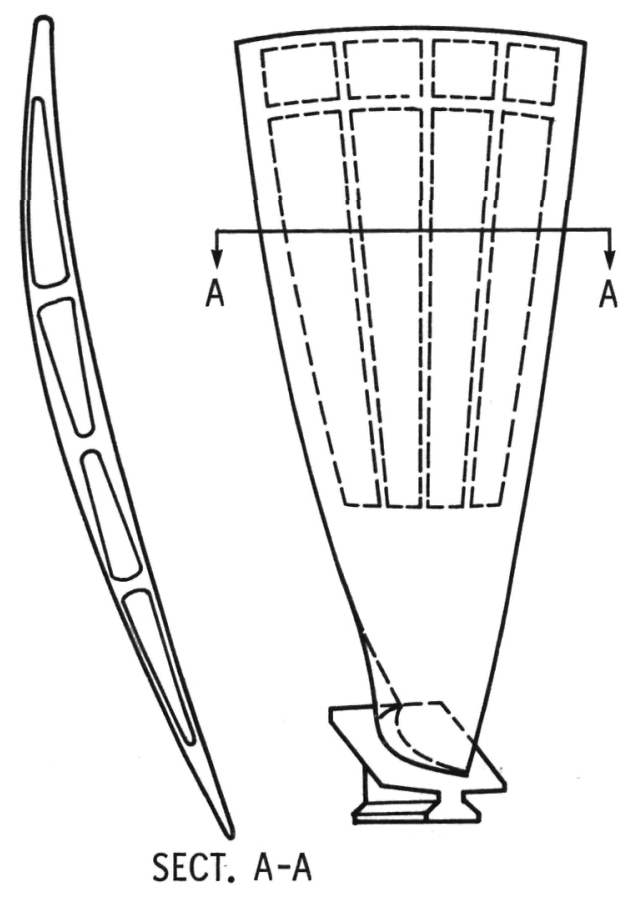

Figure 1. - A hollow fan blade configuration.

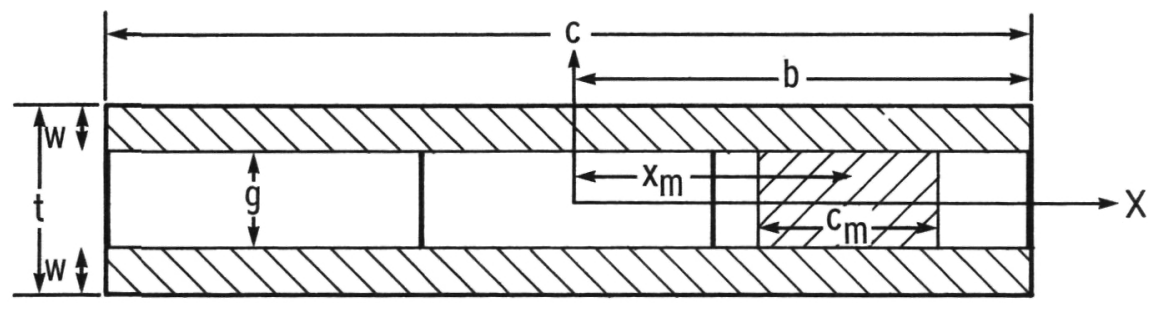

Figure 2. - Idealized fan blade section 


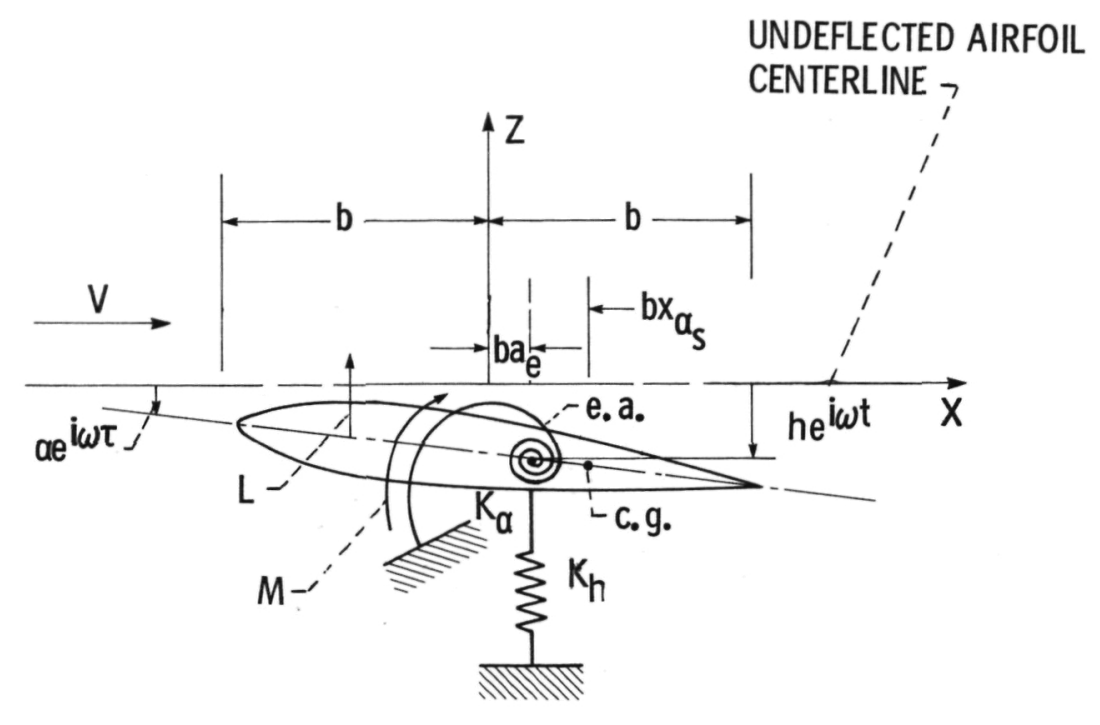

Figure 3. - Airfoil restrained from bending and torsional motion (sinusoidal wakes not shown). 


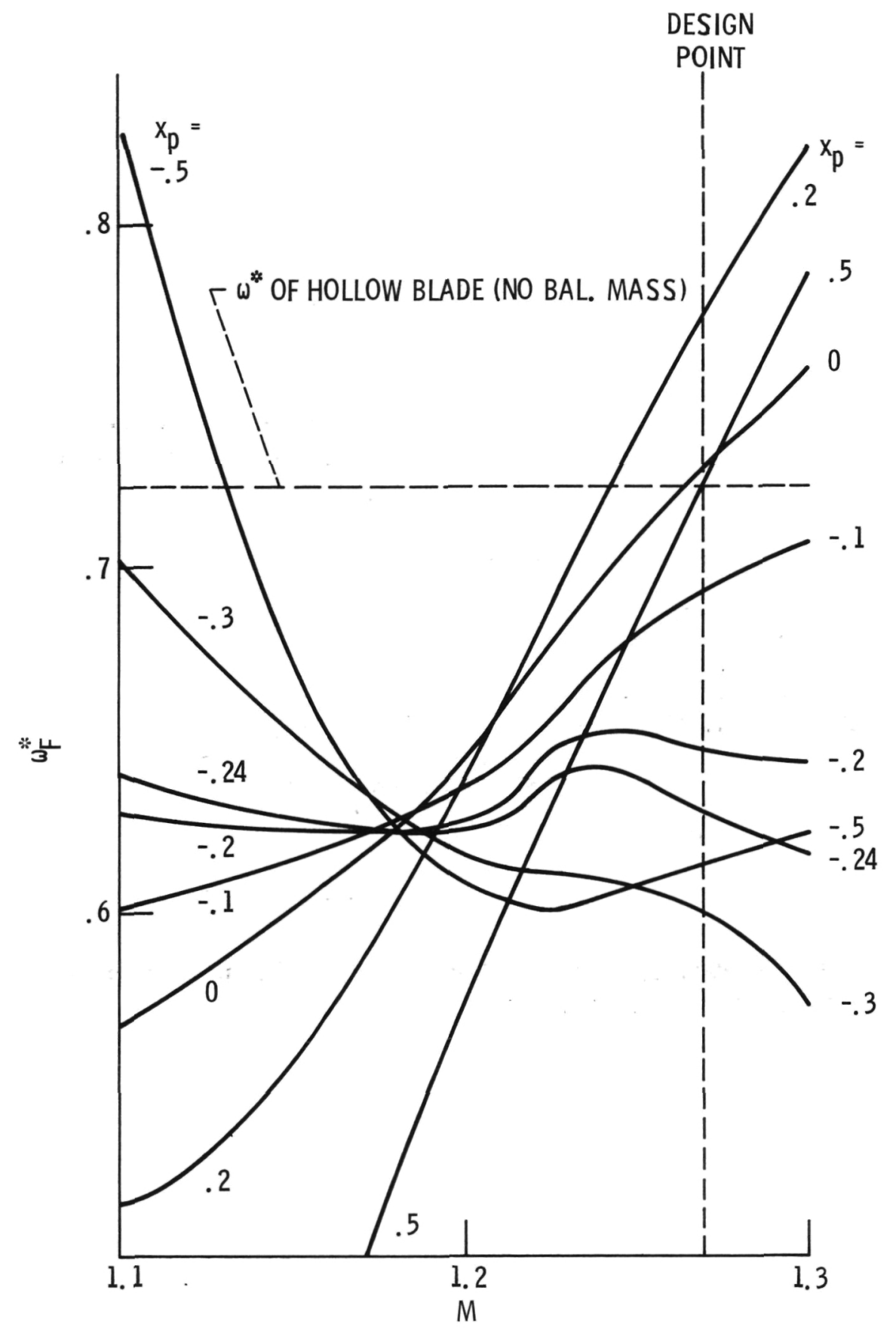

Figure 4. - Effect of pitching axis location on flutter frequency $(\xi=64.68 \mathrm{deg}, s / c=0.8)$. 


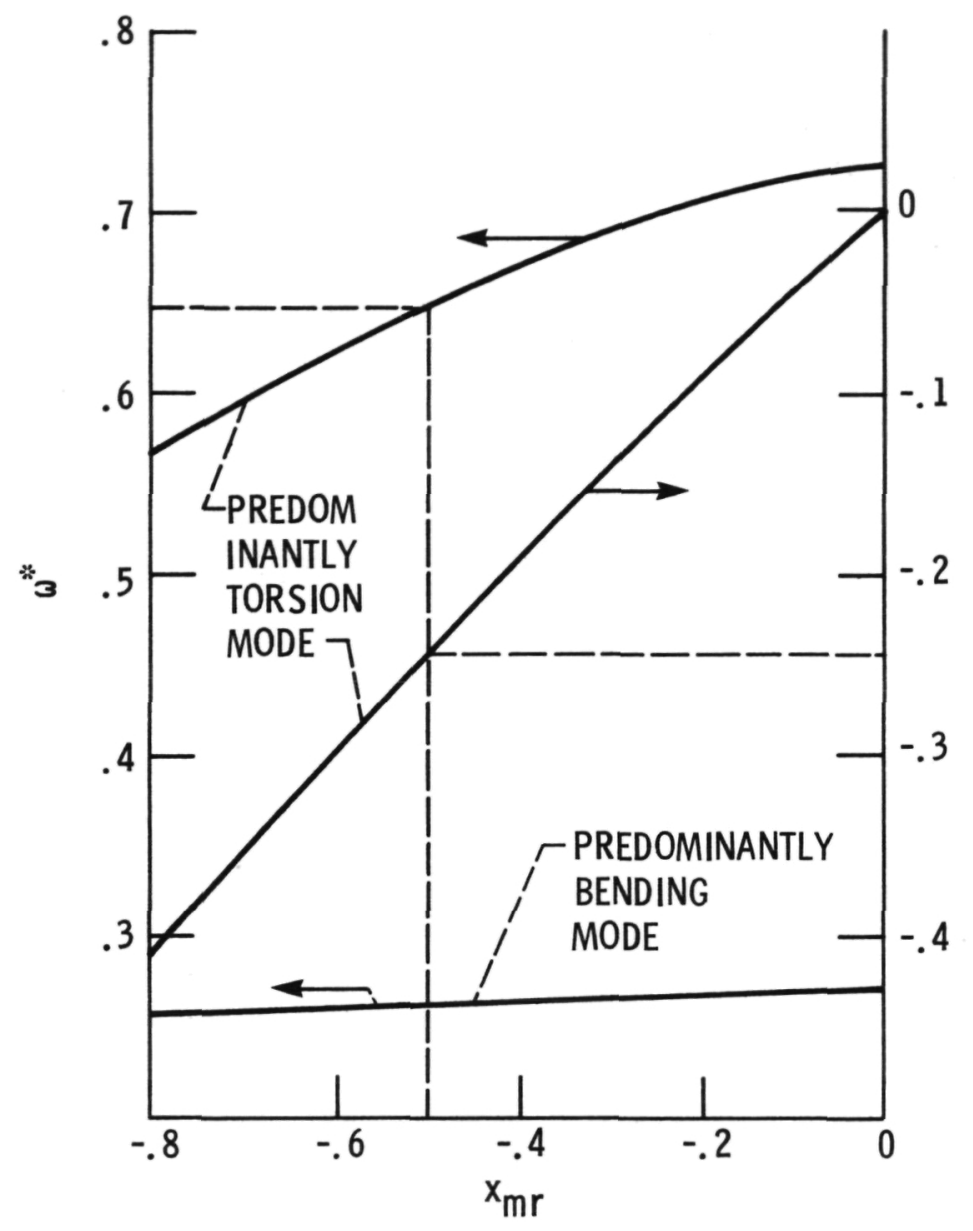

Figure 5. - Effect of mass balancing location on blade frequencies and pitching axis location $\left(c_{\mathrm{mr}}=0.22, P_{\mathrm{mr}}=4\right)$. 


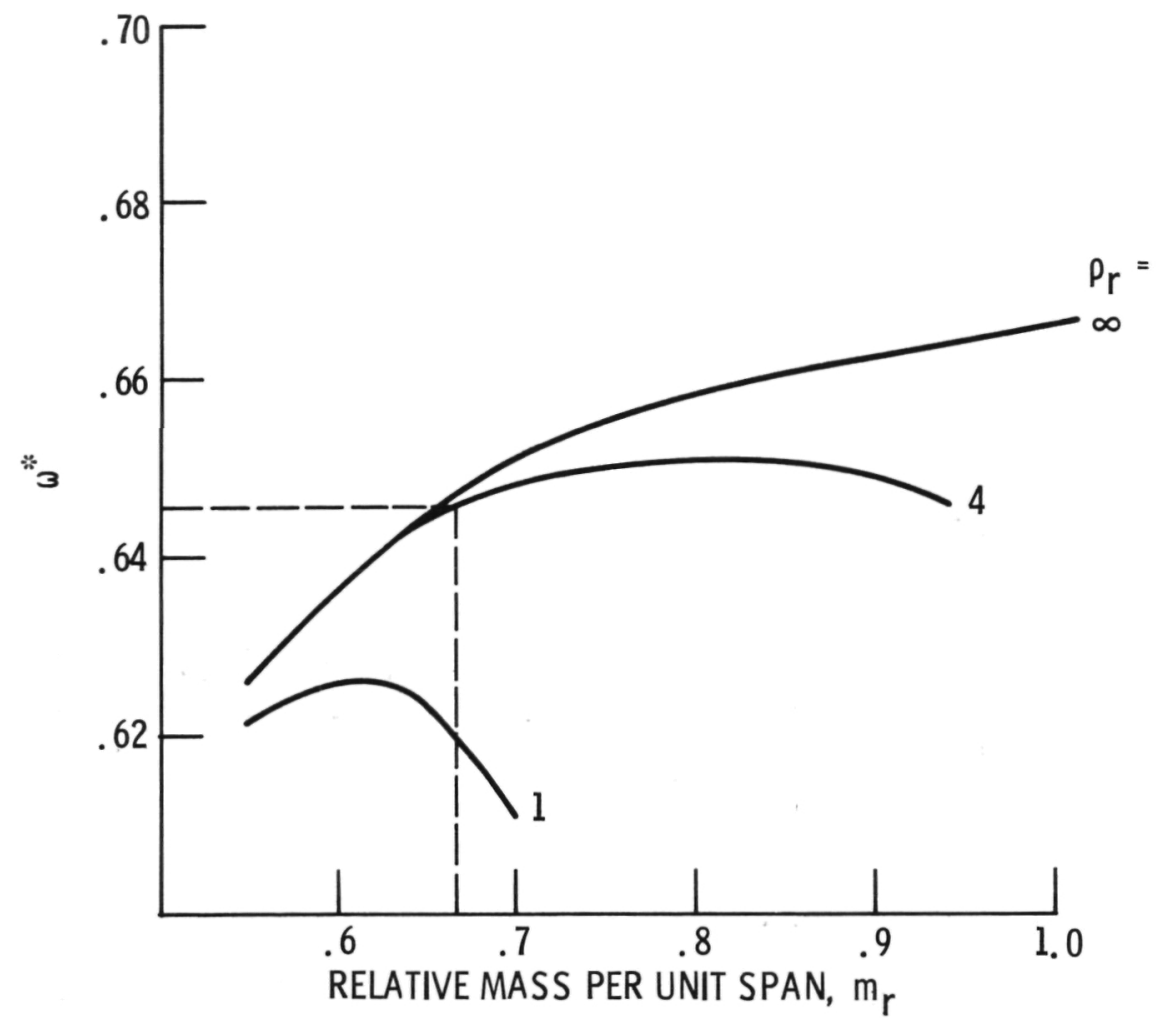

Figure 6. - Dependence of frequency on blade mass $\left(x_{p}=\right.$ $-0.24)$.

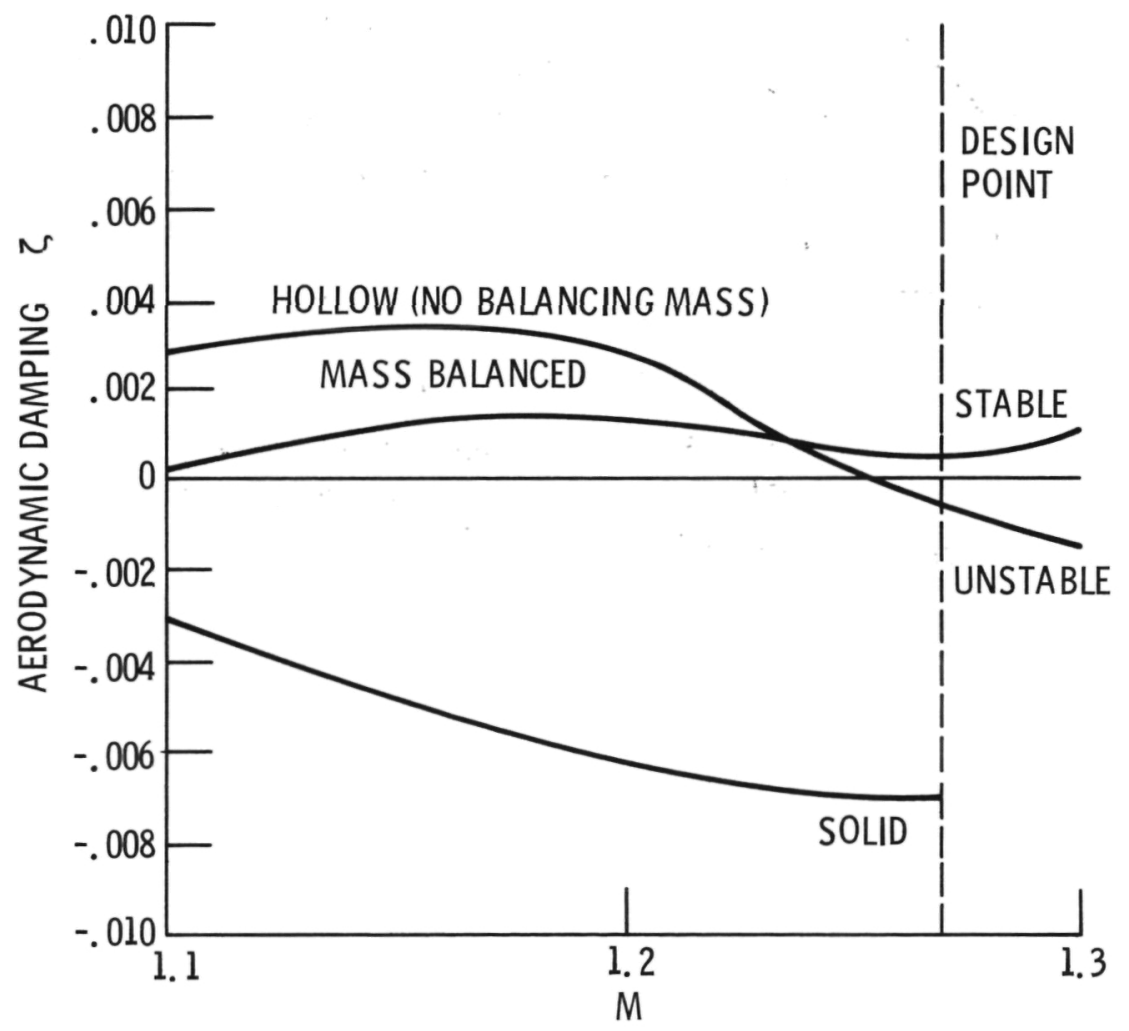

Figure 7. - Aerodynamic damping for solid and hollow blades. 


\begin{tabular}{|c|c|c|c|}
\hline $\begin{array}{l}\text { 1. Report No. } \\
\text { NASA TM-87197 }\end{array}$ & 2. Government Accession No. & \multicolumn{2}{|c|}{ 3. Recipient's Catalog No. } \\
\hline \multicolumn{2}{|l|}{ 4. Title and Subtitle } & \multicolumn{2}{|l|}{ 5. Report Date } \\
\hline \multicolumn{2}{|c|}{ Mass Balancing of Hollow Fan Blades } & \multicolumn{2}{|c|}{$\begin{array}{l}\text { 6. Performing Organization Code } \\
505-33-7 B\end{array}$} \\
\hline \multirow{2}{*}{\multicolumn{2}{|c|}{$\begin{array}{l}\text { 7. Author(s) } \\
\text { Robert E. Kielb }\end{array}$}} & \multicolumn{2}{|c|}{$\begin{array}{l}\text { 8. Performing Organization Report No. } \\
\text { E-2851 }\end{array}$} \\
\hline & & \multicolumn{2}{|l|}{ 10. Work Unit No. } \\
\hline \multicolumn{4}{|c|}{ 9. Performing Organization Name and Address } \\
\hline \multicolumn{2}{|c|}{$\begin{array}{l}\text { National Aeronautics and Space Administration } \\
\text { Lewis Research Center } \\
\text { Cleveland, Ohio } 44135\end{array}$} & \multicolumn{2}{|c|}{ 11. Contract or Grant No. } \\
\hline \multicolumn{2}{|l|}{ 12. Sponsoring Agency Name and Address } & \multicolumn{2}{|c|}{$\begin{array}{l}\text { 13. Type of Report and Period Covered } \\
\text { Technical Memorandum }\end{array}$} \\
\hline \multicolumn{2}{|c|}{$\begin{array}{l}\text { National Aeronautics and Space Administration } \\
\text { Washington, D.C. } 20546\end{array}$} & \multicolumn{2}{|c|}{ 14. Sponsoring Agency Code } \\
\hline \multicolumn{4}{|l|}{ 15. Supplementary Notes } \\
\hline \multicolumn{4}{|c|}{$\begin{array}{l}\text { Prepared for the } 31 \text { st International Gas Turbine Conference, sponsored by the } \\
\text { American Society of Mechanical Engineers, Dusseldorf, West Germany, June } 8-12 \text {, } \\
1986 \text {. }\end{array}$} \\
\hline \multicolumn{4}{|c|}{$\begin{array}{l}\text { 16. Abstract } \\
\text { This paper uses a typical section model to analytically investigate the effect } \\
\text { of mass balancing as applied to hollow, supersonic fan blades. A procedure to } \\
\text { determine the best configuration of an internal balancing mass to provide flutter } \\
\text { alleviation is developed. This procedure is applied to a typical supersonic } \\
\text { shroudless fan blade which is unstable in both the solid configuration and when } \\
\text { it is hollow with no balancing mass. The addition of an optimized balancing mass } \\
\text { is shown to stabilize the blade at the design condition. }\end{array}$} \\
\hline \multirow{2}{*}{$\begin{array}{l}\text { 17. Key Words (Suggested by Author(s)) } \\
\text { Flutter } \\
\text { Aeroelasticity } \\
\text { Blades }\end{array}$} & & \multirow{2}{*}{\multicolumn{2}{|c|}{$\begin{array}{l}\text { 18. Distribution Statement } \\
\text { Unclassified - unilimited } \\
\text { STAR Category } 39\end{array}$}} \\
\hline & $\begin{array}{l}\text { Un } \\
\text { ST }\end{array}$ & & \\
\hline $\begin{array}{l}\text { 19. Security Classif. (of this report) } \\
\text { Unc lass if ied }\end{array}$ & $\begin{array}{l}\text { 20. Security Classif. (of this page) } \\
\text { Unc lass if i e }\end{array}$ & 21. No. of pages & 22. Price* \\
\hline
\end{tabular}

*For sale by the National Technical Information Service, Springfield, Virginia 22161 


\section{Lewis Research Center}

Cleveland. Ohio 44135

\section{Official Business}

Penalty for Private Use $\$ 300$

\section{ADDRESS CORRECTION REQUESTED}

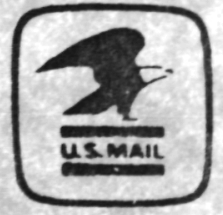

Postage and Fees Paid National Aeronautics and Space Administration NASA-451 